\title{
The Problems and Suggestions for the Development of Science and Technology Intermediaries in China
}

\author{
Lvcheng Li \\ School of Management \\ Wuhan University of Technology \\ Wuhan, China \\ lilvcheng@126.com
}

\author{
Guoping Cheng \\ School of Management \\ Wuhan University of Technology \\ Wuhan, China \\ Chenggp@whut.edu.cn
}

\begin{abstract}
The science and technology intermediary plays an important role in national innovation system, which can promote the technology transfer. This paper analyzes the current situation and the problems of the development of science and technology intermediaries in China, including imperfect function, irrational human resource structure, imbalance regional development, imperfect policies and little attention from universities and enterprises. Then some suggestions are given: improve and clarify the functional position of S\&T intermediaries; strengthen the introduction and training mechanism of S\&T intermediary talents; form a pattern that S\&T intermediaries develop in multilevels and multi-regions; establish policy and regulation system related to $S \& T$ intermediaries; increase the propaganda of the role and function of $S \& T$ intermediaries to the universities and enterprises. These countermeasures would help to the formation of S\&T intermediary system in China.
\end{abstract}

Keywords—science and technology intermediaries; problems analysis; suggestions

\section{INTRODUCTION}

A country's economic development is dependent on the strong and progressive technology. The strong technology requires the independent innovation, the collaborative innovation and the transformation of scientific and technological achievements of the different organizations in innovation system. As important platforms for the knowledge and technology transfer, science and technology intermediaries (S\&T intermediaries) are important for the construction of the national innovation system and they can promote the implementation of national science and technology innovation strategy. They have the functions of technology diffusion, achievement transformation, scientific and technological assessment, innovative resource allocation, innovative decision making and management consulting, etc. They can effectively provide support for scientific and technological activities while reducing the risk of technological transformation to promote the national innovation ability[1]. China always regards the scientific and technological innovation as the foundation of the country. The science and technology intermediaries and technology transfer service agencies are the important links in the construction of innovation system. This paper analyzes the current situation and the problems of the development of science and technology intermediaries in China and gives some suggestions.
In recent years, there have been plenty of studies of S\&T intermediaries in China. Guo Yuanyuan et al(2014) conducted the study of S\&T intermediaries from the perspective of cluster network and argued that the S\&T intermediaries have functions of searching cognition, communication absorption and commercialization and the science and technology intermediaries that occupying the structural hole can optimize the allocation of cluster resources[2]. Jiang Yongkang \& Mei Qiang(2014) believed that science and technology intermediaries have the characteristics of independence, neutrality, professionalism and knowledge-intensive, which can solve the obstacles of information asymmetry, information isolation and professional difference so as to promote innovation efficiency in the regional system[3]. Cao Yang et al (2007) presented that science and technology intermediaries serve as links in national innovation systems which can compensate for weak nodes in the system and optimize the overall system[4]. Guo Xinghua \& Li Zhengfeng(2014) hold the view that the role of science and technology intermediary in China is changing from the single role of knowledge transfer to the multi-role of knowledge transfer, knowledge production and knowledge application. They also suggested that the service system of science and technology intermediaries should be constructed[5]. Bian Weijun \& Luo Gongli(2009) analyzed the influencing factors of science and technology intermediaries in China from the aspects of government, universities and scientific research institutions, industry associations, science and technology intermediaries, environment and other institutions in the same industry [6].

\section{PRESENT SitUATION AND PROBLEMS OF S\&T INTERMEDIARIES IN CHINA}

\section{A. Present situation of S\&T intermediaries in China}

In recent years, China has paid more attention to the transformation of scientific and technological achievements and S\&T intermediaries. Ministry of Science and Technology of China released a document "Views on the development of science and technology intermediaries" in 2002, which noticed that S\&T intermediaries in China mainly conclude productivity promotion centers, science and technology business incubators, technology consultation and evaluation agencies, technology trading institutions, venture capital 
service organizations[1]. Although there are varieties of S\&T intermediaries in China, the effect of promoting technology achievement transformation has not reached the ideal state. Ministry of Science and Technology of China released a report "The statistical analysis of 2014 national main science and technology program achievements transformation and application". The Ministry investigated 9302 national projects, of which only 4396 had been transformed. The transformed projects which were transferred through the S\&T intermediaries only accounted for less than $40 \%$ [7]. Figure 1 shows the distribution of the number of transformed projects through various types of intermediaries. We can figure out that 782 projects were transformed through the industry association, which had the greatest number of transformation projects in all the technology intermediaries. Its promotion effect was the most obvious. Industry technology alliance, university science park, technology business incubator and technology trading market followed and they also had active roles. Only 154 projects were transformed through productivity promotion center which had the least number of transformed projects. Other types of intermediaries and institutions transformed 323 projects. However, most of the projects were not transformed through the science and technology intermediaries. It indicates that the function of S\&T intermediary is limited and it is potential to improve it.

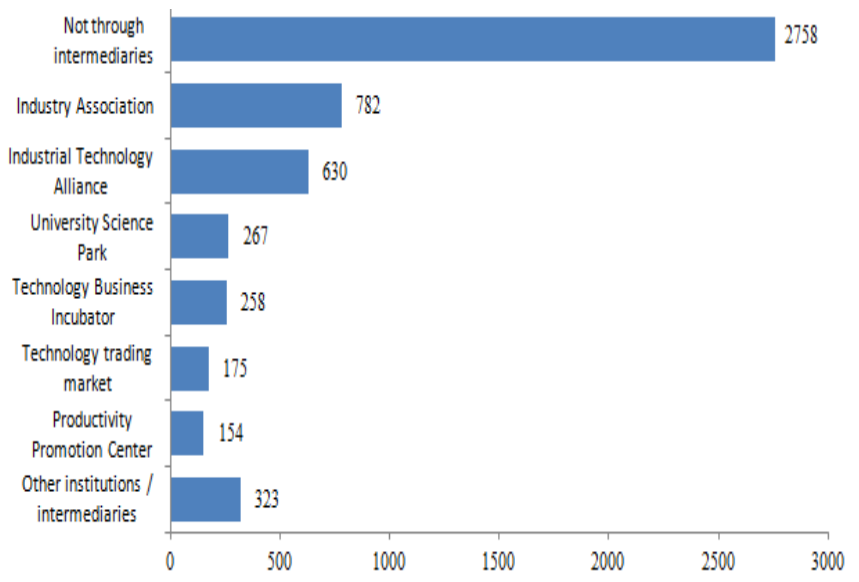

Fig. 1. Distribution of the number of transformed projects through various types of institutions / intermediaries (2014)

(Data resource: the statistical analysis of 2014 national main science and technology program achievements transformation and application, Ministry of Science and Technology of China)

\section{B. Problems of S\&T intermediaries in China}

At present, the development of science and technology intermediary in China is still in the initial stage. There are series of problems: the few varieties of the operation models, the unclear mechanism, the imperfect supporting policies and so on. The S\&T intermediaries have not fully reflected their value in the national innovation system. The detail problems are as follows:

\section{1) The function of science and technology intermediary is not perfect}

At present, some S\&T intermediaries in China do not keep up with the pace of the times. The development models of
S\&T intermediaries are restricted by external conditions so they are not easy to make progress. Although there are many types of S\&T intermediaries in China, the functional position of each type is not clear. There is no stable target customer group for different intermediaries. As the specialization level of technical consulting, venture capital and other services is not high, the credibility of S\&T intermediary is in an undesirable situation. The colleges and enterprises do not have enough confidence to conduct technology transfer activities through S\&T intermediaries. At the same time, technical method of S\&T intermediary is limited. Although some S\&T intermediaries use the internet to provide services, the effect is unsatisfying due to the inadequate investment, unprofessional staff and other reasons.

\section{2) The human resource structure of S\&T intermediary is irrational}

Human resource is one of the most important factors influencing the operation of an institution in the era of knowledge economy. Different from the general intermediary organizations, S\&T intermediaries are knowledge-intensive organizations with the function of knowledge and technology transfer. Therefore, it requires the staff of S\&T intermediaries to have professional knowledge so as to conduct technical assessment, technical advice and other tasks. A good S\&T intermediary team should consist of talents with different skills and knowledge such as professional science and technology, management, law and other subjects. At present, the human resource structure of S\&T intermediary in China is often relatively simple. The S\&T intermediaries do not have the background of professional and interdisciplinary knowledge and they have not given full play to their functions.

\section{3) The development of S\&T intermediary is imbalance in different regions}

Due to history, resource and other reasons, the regional economic development and science resources allocation are imbalance in China. There are many universities and research organizations in big cities such as Beijing, Shanghai, Nanjing and Wuhan, which become the cradle of scientific and technological achievements. Many S\&T intermediaries are also gathered in these areas. But there are few S\&T intermediaries in undeveloped areas[8]. This arrangement will not help to the formation and development of the national S\&T intermediary system. Although the science and technology lags behind, the undeveloped areas have their own advantages due to their regional characteristics. The S\&T intermediaries are important to fully demonstrate the advantages in these regions. If there is no S\&T intermediary in these areas, the innovation efficiency of the regional system will be limited.

\section{4) Supporting policies and regulations are not perfect}

Although the Chinese government has attached the importance to S\&T intermediary and formulated many relevant policy documents, which are beneficial for the development of S\&T intermediaries. But these policy documents are often at the macro level, there is no specific method and rule at operation level. At present, S\&T intermediary market in China is not standardized and stable. There is no specific operation process regulation or unified 
evaluation indicator showed in formal policy documents. The high-quality and low-quality organizations are in the market at the same time. The customer trust level is not high and it is difficult to be established, which constrains the S\&T intermediaries to have a further development.

\section{5) Universities and enterprises pay little attention to $S \& T$ intermediaries}

On the one hand, science and technology intermediary has its own objective problems and defects such as imperfect function, weak professional ability and so on. On the other hand, it restricts the development of S\&T intermediaries that enterprises and universities have not paid enough attention to the science and technology intermediaries. The staff in universities and enterprises may focus on their own research and job but not attach importance to the technology transfer. They even do not know the detail function of S\&T intermediaries. Due to this reason, they prefer to conduct technology transfer activities by themselves rather than seek help from intermediaries. This situation is likely to cause a vicious circle, the less attention and trust the enterprises and universities give to S\&T intermediaries, the less progress the S\&T intermediaries will make.

\section{SUGGESTIONS FOR THE DEVELOPMENT OF S\&T INTERMEDIARIES IN CHINA}

\section{1) Improve and clarify the functional position of $S \& T$ intermediaries}

China should improve the function and operation mechanism of S\&T intermediaries, which makes the services of S\&T intermediaries more diversified, professional and standardized. If the situation is improved, universities and enterprises are more willing to seek the help from S\&T intermediaries rather than to transform achievements by themselves in the process of technology transfer. At the same time, it should give a clear functional position for the different types of science and technology intermediaries. Different types of S\&T intermediaries have their own distinct advantages and characteristics, which make the function division more obvious. When universities and enterprises carry out different technology transfer activities, they can seek specific types of S\&T intermediaries for help and it will improve the efficiency of the transformation of scientific and technological achievements.

\section{2) Strengthen the introduction and training mechanism of S\&T intermediary talents}

There is no doubt that the quality of employees is the important influencing factor for the development of S\&T intermediaries. It should step up the recruitment of highquality professionals from different industries to work in S\&T intermediaries and form a excellent composite background team. In order to introduce high-quality talents, a series of incentives should be adopted. For example, it should raise the salaries of S\&T professionals and encourage relevant technology transfer staff to obtain a portion of the profits from the successful industrialization of the technological achievements, which will improve the enthusiasm of S\&T intermediary staff and attract other professional talents to work in the S\&T intermediaries. At the same time, it can open the training class and workshop for the staff with single knowledge structure on a regular basis, such as strengthening the commercialization knowledge for experts in the field of technology, which makes the knowledge structure of staff in S\&T intermediaries more reasonable.

3) Form a pattern that S\&T intermediaries develop in multilevels and multi-regions

S\&T intermediaries in China should develop in multi-level and multi-regional direction. In the developed areas and cities, such as Beijing, Shanghai, Nanjing, Wuhan, etc., it should establish large-scale science and technology intermediaries, which play the role of regional demonstration and affect other small intermediaries. But at the same time, we can't ignore the development of S\&T intermediaries in the undeveloped areas. It should establish some small and medium S\&T intermediaries with distinctive characteristics associated with local industry characteristics, which will promote the industry development in the areas. Meanwhile, science and technology intermediaries in the region should built relationship with each other to establish information flow mechanism. It is beneficial for the formation of national science and technology intermediary system with Chinese characteristics.

\section{4) Establish policy and regulation system related to S\&T intermediaries}

Chinese government should release detail regulations related to S\&T intermediaries. It should clear the position of S\&T intermediaries in the market that the S\&T intermediaries can develop independently in the market and realize their own value through market self-regulation. At the same time, it should standardize the operation of S\&T intermediaries through laws and regulations to improve the entry threshold of S\&T intermediary industry. In detail, a clear and formal industry standard of the operation process, evaluation indicators, profit allocation of the technology transfer achievements should be given, which can improve the overall quality of S\&T intermediary services and strengthen the confidence for the universities and enterprises to cooperate with intermediaries.

\section{5) Increase the propaganda of the role and function of $S \& T$ intermediaries to the universities and enterprises}

Besides the relevant policies and regulations, it is also essential to increase the propaganda of the importance of technology transfer and S\&T intermediaries. The relevant staff in government and technology intermediaries should go to relevant colleges, universities and enterprises regularly to carry out publicity activities, indicating the reliability and advantages of technology transfer through S\&T intermediaries. It is best to demonstrate the successful cases of technology transfer so as to strengthen the confidence of universities and enterprises to transfer technology through S\&T intermediaries. This requires the cooperation of government, S\&T intermediaries, universities and enterprises.

\section{SUMMARY}

This paper argues that the science and technology intermediary plays an important role in the national innovation system. We analyze the current situation of the science and technology intermediaries in China and put forward that the 
science and technology intermediaries in China have not fully played their role. Then we point out some problems for the development of S\&T intermediaries. Finally, we give some suggestions for the development of S\&T intermediary in China: (1)Improve and clarify the functional position of S\&T intermediaries; (2)Strengthen the introduction and training mechanism of S\&T intermediary talents; (3)Form a pattern that S\&T intermediaries develop in multi-levels and multiregions; (4)Establish policy and regulation system related to S\&T intermediaries; (5)Increase the propaganda of the role and function of S\&T intermediary to the universities and enterprises.

\section{REFERENCES}

[1] Ministry of Science and Technology of China. Views on the development of science and technology intermediaries[EB/OL]. (200212-20).

http://www.most.gov.cn/fggw/zfwj/zfwj2002/200512/t20051214_54981. htm. (In Chinese)

[2] GUO Yuanyuan,CHI Renyong \& DUAN Shan. S\&T intermediary function, network position and performance of industry cluster:evidence from typical industry clusters in Zhejiang Province[J]. Studies in Science of Science, 2014, 32(6):841-851. (In Chinese)
[3] JIANG Yongkang \& MEI Qiang. Research on coupling mechanism of science and technology intermediary's characteristics and regional innovation capability[J]. Scientific Management Research, 2014, 32(3):72-75. (In Chinese)

[4] CAO Yang, CHEN Shijun \& WANG Xueping. Research on the functions orientation in national innovation system and the running mechanism of science and technology intermediary[J]. Science of Science and Management of S.\& T., 2007, (4):20-24. (In Chinese)

[5] GUO Xinghua \& LI Zhengfeng. Research on role evolution and policy selection of Science and technology intermediary from the perspective of open innovation[J]. Scientific Management Research, 2014, 32(3):5-8 (In Chinese)

[6] BIAN Weijun \& LUO Gongli. Drivers and suggestions on S\&T intermediate construction-based on survey questionnaires from Shandong province[J]. Economic Problems, 2009, (7):40-43. (In Chinese)

[7] Ministry of Science and Technology of China. The statistical analysis of 2014 national main science and technology program achievements

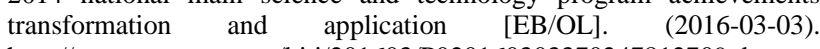
http://www.most.gov.cn/kjtj/201603/P020160303370247812709.doc. (In Chinese)

[8] LIU Feng, WANG Yongjie \& Chen Guang. Research on the international comparison and development trend of science and technology intermediary organizations in China[J]. Forum on Science and Technology in China, 2005, (3):49-53. (In Chinese) 